\title{
Postdigital Education in Design and Practice
}

\author{
Tim Fawns ${ }^{1}$ (D) \\ Published online: 28 November 2018 \\ (C) The Author(s) 2018
}

\begin{abstract}
Digital education is one of a number of terms (including e-learning, technologyenhanced learning, online learning, blended learning) that have seen increasing use in educational discourse and in the branding of educational programmes. A lack of conceptual clarity around such terms makes it easier for different groups to appropriate them in the service of conflicting agendas. In this paper, I discuss the pros and cons of the tendency to distinguish between digital and non-digital, arguing that while concepts like "digital education" can be useful insofar as they encourage people to look closer at the design and practice of teaching and learning, they become problematic when used to close down ideas or attribute essential properties to technology. Considering the implications for understanding institutional initiatives, student practices, and the interplay between teaching design and orchestration, I argue for a postdigital perspective in which all education - even that which is considered to lie outside of digital educationtakes account of the digital and non-digital, material and social, both in terms of the design of educational activities and in the practices that unfold in the doing of those activities.
\end{abstract}

Keywords Digital education · e-Learning · Design · Teaching · Learning analytics · Institutional agendas

\section{Introduction: Terminology and Troublesome Distinctions}

Where does learning happen? Techno-centric terms like e-learning, online learning and digital education can imply that it happens in a virtual space, independent of the physical and material constraints of the "real world". In many cases, these terms

Tim Fawns

tfawns@ed.ac.uk

1 Edinburgh Medical School, University of Edinburgh, 49 Little France Crescent, Edinburgh EH16 4SB, UK 
characterise learning that is enabled via computerised tools and is presumed to happen outside of classrooms or lecture theatres (e.g. Aparicio et al. 2016). Conversely, face-toface teaching implies that learning happens when two or more people engage in synchronous conversation or interaction and, despite the common use of videoconferencing technology such as Skype, the faces are physically collocated, usually within a classroom (e.g. Feenberg 2017; Rose 2017). Labelling certain kinds of education as traditional (e.g. Vavpotič et al. 2013) obscures the fact that digital technology has permeated the classroom and that, even where laptops and mobile devices are banned, digital technologies and the Internet shift not only what happens before and after the formal lesson, but the way students engage with information during class. The possibility of connecting after class shapes the very possibilities for thinking, even while not connected (Fawns and O'Shea 2018; Loader 2013). Even the concept of the flipped classroom maintains this distinction, with the primary learning taking place in the classroom, and secondary, informal learning outside it (McLaughlin et al. 2014). What all of these terms have in common is that they imply a simplistic distinction that is actually very complex. In this paper, I illustrate the ways in which certain conceptions of the relationship between technology and education can limit the design and practice of teaching as well as the effectiveness of wider institutional initiatives. I then make the argument that breaking down distinctions between digital and non-digital forms of education, and recognising that technology and education are interdependent, can support more effective teaching, as well as informing more effective institutional policy and technological investment.

\section{Digital Education (and Its Synonyms)}

An early mention of the term "digital education" was made in a paper called "Skill vs. Knowledge", read at the American Dental Association's 17th Annual Session in 1877 by Dr. W. St. George Elliott (1877: 592). It referred to differences, within dentistry, in dexterity of the left and right hands. St. George Elliott was making the point that practitioners should not rely on tools and equipment, but should also hone their physical skills and capacity for material manipulation. In the 1980s, the term was occasionally used to mean education about digital technologies and electronics more generally (e.g. Putman 1986). In the 1990s, usage of "digital education" shifted towards an understanding of digital spaces (e.g. the Internet), digital literacy, and educational approaches that made use of digital technology (e.g. Cookson 2000; Towndrow 1999). These latter conceptions are still evident, but it has also, more recently, been used as a substitute for terms such as e-learning, which has developed connotations of technology-driven, instructional training modules (e.g. Clark and Mayer 2016); technology-enhanced learning, which has developed connotations of instrumentalism (Bayne 2015; Kirkwood and Price 2014); blended learning, which, as Oliver and Trigwell (2005) pointed out, fails to discriminate between different approaches; and online learning, which has become largely synonymous with distance learning (e.g. Herrington et al. 2001) as a mode of education that does not feature the synchronous, physical, co-location of students and teachers (Feenberg 2017; Sherry 1995). The Masters of e-Learning at the University of Edinburgh, for example, became the MSc Digital Education in an 
attempt to convey a more holistic sense of the implications of our increasingly intimate relationship with technology and media.

Emerging postdigital perspectives, championed by the journal of Postdigital Science and Education in which this article is published, reject the notion that education can ever be entirely online or digital; instead, it always involves the combination of digital, biological, material and social (Jandrić et al. 2018). This perspective also brings into question the possibility of entirely "face-to-face" courses (Gourlay et al. 2015) or of distinguishing blended learning from any other kind of learning (Oliver and Trigwell 2005). With the possible exception of groups that have somehow managed to entirely eschew digital technology in their day-to-day lives, contemporary face-to-face learning is blended learning for all intents and purposes. As Bayne argued, "the digital is not a special or separate domain from embodied, co-present spaces that we inhabit day to day - instead, the two kinds of spaces are inextricably linked with each other" (Bayne and Jandrić 2017: 14-15). A view of all teaching as incorporating digital and material activity provides a useful lens for examining sweeping criticisms or endorsements of the use of technology in education. For example, consider Hubert Dreyfus' objections to what he called distance learning, but which might also be called online learning, elearning or distance education. In 2009, he wrote that "it is now clear that distance learning has failed. The major universities have given up on it and consider their investments of hundreds of thousands of dollars as sunk cost." (Dreyfus 2009: 11).

Leaving aside the questionable claims that "distance learning has failed" or that "universities have given up on it", Dreyfus' argument about why the huge financial investments made by universities have not produced much in the way of clear value was based on the notion that learning through the digital interface of the Internet cuts learners off from embodied and emotional connection to the environment, which he claims are the basis of understanding. As Ward (2018: 4) pointed out, "Dreyfus correctly directs our attention to the importance of embodied interaction in learning, but draws the wrong morals from his reflections". After all, as Ward argued, emotional engagement in computer-mediated interactions is not only possible but common.

Dreyfus' worry that "we enter cyberspace and leave behind our emotional, intuitive, situated, vulnerable, embodied selves" (2009: 6-7) exemplifies this strange notion that digitally mediated learning is somehow located in a separate reality from other kinds of education. As Ward wrote, "our embodied, affective grip on our situation is not a dispensible feature of our relation to the world that can be checked at the door when we go online" (2018: 12). ${ }^{1}$ The main problem with Dreyfus' argument is that he assumed digital learning to constitute all of the learning, rather than acknowledging that online interactions are just pieces of a much more complex puzzle, made up of inextricably interconnected social and material activity. Likewise, Ward, in arguing for scaffolding affective and embodied interactions into online learning, risked missing this bigger picture: that scaffolding itself is sociomaterial (Fenwick 2015) - it is neither online nor offline but distributed between learner, teacher and social, material and digital world. Learning spills out beyond the classroom and the computer, blending face-to-face and online, asynchronous and synchronous, bodily and cognitive forms.

\footnotetext{
${ }^{1}$ Interestingly, by making such context-independent claims about online learning, Dreyfus ironically positions himself - in his own terms - as an online learning novice (Dreyfus and Dreyfus 1980) and thus ill-equipped to offer commentary.
} 
By drawing a clear boundary between online and face-to-face modes, both Ward and Dreyfus, while arguing different views, have overly constrained the boundaries of learning, and this has coloured their arguments about what online learning can and cannot do. Ward's argument that online learning can involve affective and bodily engagement could be more compellingly reframed to highlight that the distinction between face-to-face and online is limited to particular instances of interaction rather than overall programmes of learning. One leaves the classroom and continues to learn, often using digital media (or one uses it while still in the classroom). One stops attending to digital media and continues learning within the physical world, which is often embodied by other people who constitute part of the learning environment. From this view, no meaningful claim at all can be made about "online learning", other than that it must involve some connection to the Internet at some point.

\section{Institutional Initiatives in Digital Education}

Interestingly, however, Dreyfus' (2009: xi) view that "distance learning has failed" reflects a broader economic disappointment in the outcomes of technology-driven initiatives. The problem at the centre of this issue is that technology is often introduced into educational activities with inappropriate expectations or understandings, as if it can, through its functionality, bypass complex and contextual challenges (Veletsianos and Moe 2017). As Selwyn has noted, technology-based or digital approaches are often proposed as the solution to problems of scalability, efficiency and cost savings (Selwyn 2007), as well as accessibility and fairness (Selwyn 2010). A view of educational technology as "technologies that do the educating" (Feenberg 2017: 364) can be appealing to institutional administrative authorities with its promise of economic rationalisation and cost savings. At the same time, particular rhetorical uses of the term "digital" can also be harnessed to generate cultural capital (Bourdieu 1986) by making educational programmes seem more up-to-date and innovative. For example, the University of Edinburgh's (2016) Strategic Plan endorses "a digital culture that will culminate in a university where: every core service is fully digital; every educator is a digital educator; [and] every student is a digital student".

Here, being digital is portrayed by the institution as inherently positive, requiring transformation from an inferior, pre-digital state. This language establishes a very different position from that taken up by Dreyfus, who saw traditional or face-to-face teaching as inherently superior. Yet both positions suggest essentialist perspectives that can lead to crude comparisons and pervasive discourses that divide digital and nondigital education. Even Feenberg (2017: 366), for example, while arguing for the positive potential of asynchronous, text-based discussion, resorted to portraying a deficit model of online learning in which "a true equivalent of classroom interaction" is not only possible (what does equivalent mean, in this sense?), but a desirable outcome: "... there is little doubt that well prepared teachers under good conditions can be effective at sustaining a true equivalent of classroom interaction".

Feenberg went on to propose blended learning as a way to negotiate the divide between technology-driven instruction and human endeavour and, in doing so, seems to have conceded to a persistent notion that face-to-face is the optimum model and online learning is something that can - in the right circumstances - be just as good, but 
not better. Of course, as I have mentioned above, blended learning is not a discriminating concept (Oliver and Trigwell 2005) and is perhaps used by Feenberg to pacify those who find the idea of online learning unappealing. Nevertheless, such language reinforces a separation between online and face-to-face teaching. Rose (2017), too, seems to seesaw between arguing that some face-to-face teaching is necessary for authentic education, and arguing that crude claims such as this are problematic because there is a "messy" continuum of ways in which technology can be used in education. This gives an idea of the challenge that confronts educators as they negotiate different ways of talking about digital education that are often in tension.

Despite the reservations of Dreyfus, Feenberg, Rose, Selwyn and others, the literature is awash with glowing endorsements of particular technological interventions (Selwyn 2010), and it is easy to see failure to capitalise on the potential of educational technology as the fault of the teacher. A desire to design-out such failure can be seen in titles like "e-Learning and the Science of Instruction: Proven Guidelines for Consumers and Designers of Multimedia Learning" (Clark and Mayer 2016), which suggest that there are scientifically proven instructional designs that, if followed, will result in effective learning. Clark and Mayer (2016: 8) positioned successful e-learning as largely independent of the idiosyncrasies of the teachers and learners, and of the contexts in which learning happens, although they briefly acknowledged "various environmental factors, including technological, cultural, and pragmatic constraints". In doing so, they seemed to assume that designers can control or determine the activities and, ultimately, the learning of their target audience.

Selwyn (2010) and others have proposed that technology should not be seen as an independent force - either a positive or negative one - but as part of the landscape in which education is enacted. It cannot, as Jones (2013: 213) reasoned, "in any simple sense cause educational effects or any particular learner responses" (italics from the original). This does not mean that technology is inert, something that is simply used without leaving a trace on its user or its object. It is, as Kranzberg (1986: 545) proposed, "neither good nor bad; nor is it neutral". Technology and pedagogy drive each other, caught in a continuous feedback loop, and it is in the integration of new technologies and related practices into existing ecologies that opportunities and challenges arise. Any "failure of distance education" from this perspective is not due to an inherent limitation of digital technology to facilitate authentic learning, nor to the inability of teachers to wield it effectively. Rather, it is due to a failure to integrate new technologies and practices into existing educational ecologies in ways that respect and, where appropriate, preserve traditional academic practices and values (Feenberg 2017; Rose 2017).

As Rose (2017) pointed out, the expense of technological "solutions" such as virtual learning environments (VLEs) has often led to pressures, implicit and explicit, to use them. Within this pressurised environment, many educational practitioners and stakeholders have felt caught between administrative authorities and techno-enthusiasts on one hand, and traditional pedagogical values on the other, and are often unsure how to respond (Säljö 2010). Boud and Brew (2013) claimed that much of an educator's professional development arises out of the need to question and resolve changing work demands and to refine and develop their working practices. Institutional pressure to use technology in one's teaching is an example of such changing demands. However, educators may find themselves overly constrained as, according to Rose (2017: 375), 
their design choices are limited through the "very limited palette" of standardised VLEs:

... most of the important design decisions have already been made by the developers, and these decisions tend to embody particular pedagogies - specifically, those that are readily quantified - and to support and replicate existing hierarchies of knowledge and power within the institution. In short, by the time they come to us [the teachers], these technologies are far from neutral. (Rose 2017: 375)

By emphasising standardisation and scalability, institutional agendas that push the use of technology in education are at odds with the goals of many university teachers, who are focused on creating effective learning environments and quality learning experiences (Rose 2017). As Selwyn has cautioned, it may be that

the recent haste to 'implement' computer technologies in higher education teaching and learning has caused many educationalists and technologists to lose sight of the guiding principles and underlying purposes of university education. (Selwyn 2007: 90).

Ironically, much of the research evidence used to drive digital education initiatives probably comes from the influence of engaged and skilled teachers. As Selwyn pointed out, the literature is full of studies of " "model' education institutions and classrooms with enthusiastic tutors and well-resourced students" (Selwyn 2010: 70). These reports often suggest that there is a right way to do things that need only be appropriately adopted by teachers in different settings. In contrast, Enriquez (2009) provided an example of how, at an unspecified British University, the ecology within which the Blackboard virtual learning environment (VLE) was embedded was significant for the actual configurations and teaching practices that took place, which often departed from the top-down expectations of the institution:

It was growing or replicating, but not the same way in each occasion or instance. Rather, it was diversifying and there was suddenly a pressing need for staff development and support, to attend to or control the diversity that Blackboard brought with each installation and request. (Enriquez 2009: 386).

The expanding diversity of use led to attempts by the institution to standardise each course configuration, to enable streamlining of support and control of quality. Yet, according to Cuban (2001), the massive investment in educational technologies has not delivered value for money because many teachers make limited use of it as they struggle to work out how to integrate it into their teaching practice. He noted that "teachers at all levels of schooling have used the new technology basically to continue what they have always done" (Cuban 2001: 178-189).

Both Enriquez and Cuban found that teachers did not simply follow the expectations of either institution or technology designers in how they used technology in practice. Teaching practices, like any practices, involve workarounds, subversions and improvisations (Fawns and O'Shea in press). They are structured, to some extent, by 
institutional expectations and policies, but they are also situated and contextual, emerging out of a complex tapestry of conditions and parameters that cannot be predetermined. For this reason, instrumentalist notions of training, as if digital education is a matter of mechanics rather than skilled teaching, are unlikely to be successful. Boud and Brew (2013: 210) argued that it is through authentic practice of the design and performance of teaching that one really learns to develop as a teacher, and this is particularly effective where teachers are able to "extend their own practice through participation in the practices of others". Yet, in their review, Baran et al. (2011) found that formal methods of learning how to teach with technology tended to be based on traditional conceptions of teaching, without critically reflecting on how pedagogy might be reshaped to take advantage of technological possibilities. Developing more effective pedagogies will require new understandings of how digital technology is intertwined within other aspects of the spaces in which students and teachers act. Rather than looking to "identify the impediments and deficiencies that are delaying and opposing the march of technological progress" (Selwyn 2010: 69), it may be more beneficial to help teachers and students develop and embed new practices in contextually appropriate ways, while recognising and examining the "messy realities" (Selwyn 2010: 70) of technology-related practice.

\section{Design, Orchestration and Student Practices}

Even as institutions work towards standardisation of technological implementations, educational technologies have been touted as holding great potential for customising and individualising the learning experience (Säljö 2010). Much like the literature promising significant benefits of inserting technology into teaching methods, early research into learning analytics made grand promises about educational enhancements by providing access to the learning-oriented behaviour of students (Gašević et al. 2017). Learning analytics involves collecting, measuring and analysing data about learners' use of digital learning environments in order to predict and optimise their processes of learning (Long et al. 2011). This includes identifying "at risk" students, analysing social interactions and considering patterns across "traces of interaction with (learning) technologies" (Gašević et al. 2017). As Gašević and colleagues have pointed out, early results have led institutions to systematic and systemic implementations, influenced policy development and facilitated partnerships with specialist organisations.

Again, however, the promise has far exceeded the present reality (Viberg et al. 2018). Despite considerable energy and investment, the apparent potential of learning analytics has not translated into practice (Viberg et al. 2018). This may be because behavioural engagement is a poor predictor of cognitive engagement, or because, as Conijn et al. (2017: 27) argued, in many cases, "we do not really know what our measurements are actually measuring". It may also be that, while learning analytics can be used to complement or "leverage" human judgement (Viberg et al. 2018: 99), this judgement is still based on digital traces of technological interactions and, thus, on only one element - in isolation - of the activity of the learner.

Perhaps a greater challenge is that the conceptions of engagement that underpin learning analytics consider learning to be an individualised endeavour, in keeping with 
views of learning as acquisition but not as participation (Sfard 1998). Learning analytics is typically concerned with generating profiles of individuals in order to predict the trajectories and personalise the support for individual students. While individuals who learn must take something with them in terms of knowledge and skill, these outcomes of learning are manifested through contextualised, sociomaterial practice (Fawns and O'Shea in press; Fenwick 2015). In other words, learning involves both acquisition and participation (Sfard 1998). By focusing on each individual in turn, learning analytics approaches neglect how students and teachers might develop ecologies that foster productive social and collaborative interaction. Learning analytics dashboards present learning "at a glance" (Schwendimann et al. 2017), as if it is possible to reduce it to small, fully formed and meaningful representations, rather than understanding learning as something that is contextualised and that makes sense in relation to the situated activities of teachers and peers, and the environment in which that activity takes place.

By ignoring the social and material context in which learning happens, some approaches to learning analytics may be underpinned by an assumption that education can be described in digital terms, neglecting the complex interrelations between social, material and digital activity. That is not to say that there is no hope for learning analytics - indeed, digital technology can play a role in foregrounding practice by producing traces and recordings that can be revisited, and by opening up possibilities for dialogue. This is particularly important since observing practices is challenging (Nardi and O'Day 1999) and dialogue around practices is a crucial element to the development of effective ways of working and learning (Brown and Duguid 2002; Fawns and O'Shea in press). Learning analytics, then, is likely to be most effective when it complements our understanding of the context of learning, and when its practitioners take into account that not everything important is recorded or leaves a discernible, quantifiable trace.

Understanding student practices as situated and sociomaterial can help us to see that effective teaching always follows the same basic, underlying process of planning and preparation, irrespective of the format or environment. Goodyear and Dimitriadis (2013) provided a useful way to think about this process by separating out design, orchestration (responsive, on-the-fly guidance and scaffolding of learning activity) and student practice. To effectively support learning experiences, teachers need to be good at both design and orchestration, each of which involves taking into account the actual practices of the students.

Design for learning involves not only the design of tasks for students to do but also of social and physical environments in which to learn (Goodyear and Dimitriadis 2013). Importantly, the physical and social are interrelated: configuring digital technology, for example, involves configuring the digital, material and social, as all of these elements intertwine in the constitution of learning activity (Fenwick and Edwards 2016). For this reason, online courses are never just online versions of face-to-face courses (Sinclair and Macleod 2015): they must be (re) designed to take cultural and technological contexts into account. Working with digital environments can highlight challenges that have somehow become largely invisible in more traditional forms of education (i.e. that teaching preparation involves acts of design). Yet if considerations of design are more obvious in digital contexts, that is only because the novelty and dynamism of those contexts demand such considerations (Beetham and Sharpe 2013). Just like digital environments, face-to-face classrooms are configured physically and socially at the 
same time, and classroom-based teaching benefits from an explicit design process in which consideration is given to the tasks students should do, and to what materials, people and spaces they should interact with as they learn.

However, design can only provide a structure for learning activity, and Goodyear and Dimitriadis (2013) cautioned against assumptions that learners will be compliant. Even if they intend to meet the teacher's expectations, their interpretations of a task will lead to a gap between the design and the actual, emergent activity. This is complicated by the fact that, following any design of how students should learn, dynamic, situated teaching practices orchestrate (Goodyear and Dimitriadis 2013) the learning activities of the students, whether the teaching space is a physical classroom or a virtual learning environment. As students engage with the learning tasks, the teacher reinterprets the curriculum in response to various factors (e.g. student needs and attitudes, practical conditions, their own preferences, etc.), and by monitoring activity and giving feedback (Jones 2013). The scaffolding of student practices through a combination of design and orchestration is a key part of the effective operation of teachers across different learning environments. In this way, design and orchestration are also interdependent: the possibilities of orchestration are constrained by design, and ongoing configurations and future designs are informed by the actual practices of teachers and students as they unfold. For this reason, the best teaching will not divorce those designing the teaching from those orchestrating it (another argument for teachers understanding and being involved in the development of the teaching ecology).

Of course, there are limits to the influence of even the best teachers. Learning cannot be entirely predesigned, because students will not simply do what teachers want or expect, and because much of what students do happens outside formal teaching processes (Fawns and O'Shea 2018). Like teaching, learning involves innovations, workarounds and subversions, as students re-interpret formalised processes into situated practices (Fawns and O'Shea in press), even where there is extensive guidance on how they should go about their tasks (Jones 2013). Thus, while some students may benefit from clearly structured curricula, it is challenging to enforce particular kinds of engagement, particularly when these fit with the teacher's or institution's expectations at the expense of approaches that students have developed for themselves. Figuring out ways of learning - whether using digital resources or not - that work for particular situations is part of the development of the sustainable learning (Fawns and O'Shea 2018) necessary to equip students for life after graduation (Boud and Soler 2016). As such, in many cases, it is both inappropriate and impossible to entirely design and dictate the practices of students, irrespective of the extent to which technology is used. However, the point of discussing the unpredictability of practice is not that the teacher should always take a back seat in letting the students decide how to go about their learning, but that educators should take seriously the sometimes marginalised commitment to helping students learn how to learn. Therefore, design work should go beyond setting tasks and configuring environments, and include possibilities for students to configure and customise their own practices, as well as supporting the teacher's effective orchestration (Goodyear and Dimitriadis 2013).

\section{Postdigital Education?}

It is possible that terms like "digital education", "e-learning", "technology-enhanced learning", etc. have value in highlighting points of difference from "traditional" or 
"face-to-face" teaching and learning. Under the right conditions, a naïve distinction between digital and traditional education can prompt educators to more carefully consider what they are trying to achieve. Bayne (Bayne and Jandrić 2017) cites "digital culture" as an example of a term that was useful in the beginning, to promote an exploration of new ideas, but which became redundant as our understanding progressed and it was no longer necessary to examine digital and non-digital culture as distinct concepts. Similarly, it may be that some initial focus on technology is appropriate where the novelty of using it prompts educators to engage in more attentive design of learning environments and experiences, and in creative speculation around the opportunities and constraints, thereby generating an understanding from which meaningful tasks can be planned. However, design expertise is relevant not only in instances of "digital education" but in education more generally as "a natural part of on-going cycles of educational provision and enhancement" (Goodyear and Dimitriadis 2013: 3). Thus, at some point, it becomes important to progress from naïve conceptions of digital education and, indeed, non-digital education, to a recognition that considered, practically and theoretically informed design and orchestration are crucial, no matter what form teaching takes. Without progressing from a perspective in which technology is seen as separate from situated, sociomaterial activity, conceptions of digital education may remain deterministic (Selwyn 2010), shutting down possibilities for meaningful action and design (Nardi and O'Day 1999).

Against the backdrop of ecological complexity and situated practices, presented above, simplistic distinctions between education that features digital technology and that which does not begin to break down. What is required, then, is a perspective that recognises that neither learning nor teaching are, themselves, digital. Instead, interactions with digital technology are simply an integrated part of wider teaching and learning activity. This is true for online and face-to-face learning: both involve technology and embodied, affective and social experiences. This becomes clearer when we consider learning as extending over time, beyond formally scheduled occasions. Learning is not only socially and materially distributed, but also temporally, located in the context of practices one has done in the past, and others one might do in the future. Even in classrooms where digital devices are discouraged or banned, past and future technological practices shape the activity of students, for example, around decisions of whether to take notes or look up information later. Thus, the value of digital networks is not only constituted by actualised connections (those currently in play) but also by historical and potential ones (Fawns and O'Shea 2018).

Paying attention to practices can help educators to not only to assess and guide student performance but also to evaluate and refine their educational designs and the environments in which learning occurs (Fawns and O'Shea 2018), based on what they induce people to do or how they structure activity, rather than on what technology is used. A practice focus can also help avoid unproductive assumptions and generalisations (e.g. "students are good at technology" or "online students don't engage"). Responsibility and agency are not qualities inherent within the individual student but are relational (Fenwick 2015), distributed across educators, students and environments. This is important not only for designing and orchestrating meaningful learning activities but also for resisting institutional and political forces that use technology as a basis for streamlining, standardisation and efficiency, without considering how these changes manifest in the practices of students and teachers. 
One possible way forward is to take a postdigital perspective on education. As Sinclair and Hayes (2018) argue elsewhere in this issue, in order to understand what such a perspective might entail, we must first consider what is meant by "digital". In the simplest sense, digital education is education in which digitally constituted information is used. However, even digital technology is not digital in a straightforward sense - the technology itself is composed of material elements that interact with digitally constituted information. Likewise, to define digital education by the use of digitally constituted information is, nowadays, overly inclusive and indiscriminate. Almost all education, particularly if we include the formal and informal curriculum, encounters digital information in some way. What then can we do to understand the differences between approaches that are profoundly influenced by digital possibilities and those which are not? Indeed, it is the difficulty of drawing clear boundaries between the digital and the non-digital that has led me to this exploration of postdigital education in the first place. The crisis addressed by my particular use of the prefix "post(-)" (Sinclair and Hayes 2018) is that I am not sure there is anything that is purely digital, beyond the information that is stored in microchips or passed through networks, waiting to be interacted with and operated on in meaningful activity.

In any case, I would not wish to argue that we should replace all instances of "digital education", "online learning", "e-learning," etc. with some other term like "postdigital education". I suspect that whichever terms we use, they will come to mean particular things that we did not intend and that we will continue the trend of abandoning one after the other. As Taffel (2016: 335) argued, it is not the term itself that holds critical value but its utility in exposing issues within "the contemporary digital landscape". Sinclair and Hayes (2018) put it succinctly and elegantly: "the prefix post(-) signals that we have something to talk about". Thus, in discussing postdigital ideas of education, I am looking less for a linguistic shift and more for a shift in educational culture, where educators think in the same way about learning activities — critically questioning design and practice - whether they involve microchips or not. Harking back to St. George Elliott's early mention of "digital education" in his dental paper from 1877, we want to consider not only the qualities and possibilities of the available tools and equipment, but how we can develop our ability to manipulate the world around us-digitally, materially and socially. All teaching should take account of digital and non-digital, material and social. Ideas like "digital education" are useful insofar as they encourage people to look closer at what is happening, but become problematic when used to close down ideas or attribute instrumental or essential properties to technology.

In this paper, I have discussed how certain ways of conceiving of the digital (and, indeed, the traditional and face-to-face) can enable particular agendas that may not align with the educational goals of students or teachers. The uses of terminology and the kinds of discourse considered here matter because they frame much of our contemporary discussion of education (Säljö 2010). A postdigital perspective, in which the digital makes up part of an integrated totality, should encourage a more critical stance towards understanding technology in education and how it is actually being used (Selwyn 2012: 66). More than something about which we make simple decisions to use or not use, digital technology is something in which we are entangled in complex ways, and which is embedded in the wider culture. 
Acknowledgments Thanks to Christine Sinclair, Gill Aitken and Derek Jones for their helpful comments on drafts of this paper.

\section{Compliance with Ethical Standards}

Conflict of Interest The author declares that he has no conflict of interest.

Open Access This article is distributed under the terms of the Creative Commons Attribution 4.0 International License (http://creativecommons.org/licenses/by/4.0/), which permits unrestricted use, distribution, and reproduction in any medium, provided you give appropriate credit to the original author(s) and the source, provide a link to the Creative Commons license, and indicate if changes were made.

\section{References}

Aparicio, M., Bacao, F., \& Oliveira, T. (2016). An e-learning theoretical framework. Educational Technology and Society, 19(1), 292-307 http://www.jstor.org/stable/jeductechsoci.19.1.292.

Baran, E., Correia, A. P., \& Thompson, A. (2011). Transforming online teaching practice: critical analysis of the literature on the roles and competencies of online teachers. Distance Education, 32(3), 421-439. https://doi.org/10.1080/01587919.2011.610293.

Bayne, S. (2015). What's the matter with 'technology-enhanced learning'? Learning, Media and Technology, 40(1), 5-20. https://doi.org/10.1080/17439884.2014.915851.

Bayne, S., \& Jandrić, P. (2017). From anthropocentric humanism to critical posthumanism in digital education. Knowledge Cultures, 5(2), 197. https://doi.org/10.22381/KC52201712.

Beetham, H., \& Sharpe, R. (Eds.). (2013). Rethinking pedagogy for a digital age. New York: Routledge.

Boud, D., \& Brew, A. (2013). Reconceptualising academic work as professional practice: implications for academic development. International Journal for Academic Development, 18(3), 208-221. https://doi. org/10.1080/1360144X.2012.671771.

Bourdieu, P. (1986). The forms of social capital. In J. G. Richardson (Ed.), Handbook of theory and research for the sociology of education (pp. 46-58). New York: Greenwood Press.

Brown, J. S., \& Duguid, P. (2002). The social life of information. Boston: Harvard Business School Press.

Clark, R. C., and Mayer, R. E. (2016). E-learning and the science of instruction: proven guidelines for consumers and designers of multimedia learning, Fourth Edition.

Conijn, R., Snijders, C., Kleingeld, A., \& Matzat, U. (2017). Predicting student performance from LMS data. IEEE Transactions on Learning Technologies, 10(1), 17-29. https://doi.org/10.1109/TLT.2016.2616312.

Cookson. (2000). Implications of internet technologies for higher education: North American perspectives. Open Learning: The Journal of Open Distance and e-Learning, 15(1), 71-80. https://doi.org/10.1080 /026805100115489.

Cuban, L. (2001). Oversold and underused: computers in the classroom. Cambridge, Mass: Harvard University Press.

Dreyfus, H. L. (2009). On the internet (Second ed.). London: Routledge.

Dreyfus, S., \& Dreyfus, H. (1980). A five-stage model of the mental activities involved in directed skill acquisition. Berkeley: Operations Research Center, University of California.

Enriquez, J. G. (2009). From bush pump to blackboard: the fluid workings of a virtual environment. $e$ Learning, 6(4), 385-399. https://doi.org/10.2304/elea.2009.6.4.385.

Fawns, T., and O'Shea, C. (2018). Distributed learning and isolated testing: tensions in traditional assessment practices. In Proceedings of the 2018 Networked Learning Conference.

Fawns, T., and O'Shea, C. (in press). Evaluative judgement of working practices: reconfiguring assessment to support student adaptability and agency across complex settings. Italian Journal of Educational Technology.

Feenberg, A. (2017). The online education controversy and the future of the university. Foundations of Science, 22(2), 363-371. https://doi.org/10.1007/s10699-015-9444-9. 
Fenwick, T. (2015). Sociomateriality and learning: a critical approach. In D. Scott \& E. Hargreaves (Eds.), The Sage handbook of learning (pp. 83-93). Los Angeles: SAGE.

Fenwick, T., \& Edwards, R. (2016). Exploring the impact of digital technologies on professional responsibilities and education. European Educational Research Journal, 15(1), 117-131. https://doi.org/10.1177 /1474904115608387.

Gašević, D., Siemens, G., \& Rose, C. P. (2017). Guest editorial: special section on learning analytics. IEEE Transactions on Learning Technologies, 10(1), 3-5. https://doi.org/10.1109/TLT.2017.2670999.

Goodyear, P., \& Dimitriadis, Y. (2013). In medias res: reframing design for learning. Research in Learning Technology, 21, 1-13. https://doi.org/10.3402/rlt.v21i0.19909.

Gourlay, L., Lanclos, D. M., \& Oliver, M. (2015). Sociomaterial texts, spaces and devices: questioning "digital dualism" in library and study practices. Higher Education Quarterly, 69(3), 263-278. https://doi. org/10.1111/hequ.12075.

Jandrić, P., Knox, J., Besley, T., Ryberg, T., Suoranta, J., \& Hayes, S. (2018). Postdigital science and education. Educational Philosophy and Theory, 50(10), 893-899. https://doi.org/10.1080 /00131857.2018.1454000.

Jones, C. (2013). Designing for practice: a view from social science. In H. Beetham \& R. Sharpe (Eds.), Rethinking pedagogy for a digital age (pp. 204-217). New York: Routledge.

Kirkwood, A., \& Price, L. (2014). Technology-enhanced learning and teaching in higher education: what is "enhanced" and how do we know? A critical literature review. Learning, Media and Technology, 39(1), 6-36. https://doi.org/10.1080/17439884.2013.770404.

Kranzberg, M. (1986). Technology and history: "Kranzberg's laws”. Technology and Culture, 27(3), 544-560 http://www.jstor.org/stable/3105385.

Loader, P. (2013). Is my memory an extended notebook? Review of Philosophy and Psychology, 4(1), 167184. https://doi.org/10.1007/s13164-012-0123-2.

Long, P. D., Siemens, G., Conole, G., and Gašević, D. (Eds.). (2011). Proceedings of the 1st International Conference on Learning Analytics and Knowledge (LAK'11). Banff, AB, Canada: ACM.

McLaughlin, J. E., Roth, M. T., Glatt, D. M., Gharkholonarehe, N., Davidson, C. A., Griffin, L. M., ..., Mumper, R. J. (2014). The flipped classroom: a course redesign to foster learning and engagement in a health professions school. Academic Medicine, 89(2), 236-243. doi:https://doi.org/10.1097 /ACM.0000000000000086.

Oliver, M., \& Trigwell, K. (2005). Can "Blended Learning" be redeemed? e-Learning, 2(1), 17-26. https://doi.org/10.2304/elea.2005.2.1.17.

Putman, B. (1986). Digital electronics: theory, applications, and troubleshooting. Englewood Cliffs, N.J: Prentice Hall.

Rose, E. (2017). Cause for optimism: engaging in a vital conversation about online learning. Foundations of Science, 22(2), 373-376. https://doi.org/10.1007/s10699-015-9445-8.

Säljö, R. (2010). Digital tools and challenges to institutional traditions of learning: technologies, social memory and the performative nature of learning. Journal of Computer Assisted Learning, 26(1), 5364. https://doi.org/10.1111/j.1365-2729.2009.00341.x.

Schwendimann, B. A., Rodriguez-Triana, M. J., Vozniuk, A., Prieto, L. P., Boroujeni, M. S., Holzer, A., ..., Dillenbourg, P. (2017). Perceiving learning at a glance: a systematic literature review of learning dashboard research. IEEE Transactions on Learning Technologies, 10(1), 30-41. doi:https://doi. org/10.1109/TLT.2016.2599522.

Selwyn, N. (2007). The use of computer technology in university teaching and learning: a critical perspective. Journal of Computer Assisted Learning, 23(2), 83-94. https://doi.org/10.1111/j.1365-2729.2006.00204.x.

Selwyn, N. (2010). Looking beyond learning: notes towards the critical study of educational technology. Journal of Computer Assisted Learning, 26(1), 65-73. https://doi.org/10.1111/j.1365-2729.2009.00338.x.

Selwyn, N. (2012). Making sense of young people, education and digital technology: the role of sociological theory. Oxford Review of Education, 38(1), 81-96. https://doi.org/10.1080/03054985.2011.577949.

Sfard, A. (1998). On two metaphors for learning and the dangers of choosing just one. Educational Researcher, 25(4), 4-13. https://doi.org/10.2307/1176193.

Sherry, L. (1995). Issues in distance learning. International Journal of Educational Telecommunications, 1(4), 337-365 https://www.learntechlib.org/primary/p/8937/. Accessed 12 November 2018.

Sinclair, C., and Hayes, S. (2018). Between the post and the com-post: examining the postdigital 'work' of a prefix. Postdigital Science and Education, 1(1). https://doi.org/10.1007/s42438-018-0017-4.

Sinclair, C., \& Macleod, H. (2015). Literally virtual: the reality of the online teacher. In P. Jandrić \& D. Boras (Eds.), Critical learning in digital networks (pp. 77-99). New York: Springer.

St. George Elliott (1877). Skill vs. knowledge. In J. D. White, John Hugh McQuillen, George Jacob Ziegler, James William White, Edward Cameron, Kirk Lovick, Pierce Anthony (Eds.) The dental cosmos: Volume 
19. https://play.google.com/store/books/details/J_D_White_The_Dental_Cosmos?id=za81AQAAMAAJ. Accessed 12 November 2018.

Towndrow, P. (1999). The impact of digital education on TESOL. Computer Assisted Language Learning, 12(2), 157-162. https://doi.org/10.1076/call.12.2.157.5720.

University of Edinburgh (2016). Digital transformation and data. University of Edinburgh Strategic Plan 2016. https://www.ed.ac.uk/governance-strategic-planning/strategic-planning/strategic-plan/developmentthemes/digital-transformation-and-data. Accessed 12 November 2018.

Vavpotič, D., Žvanut, B., \& Trobex, I. (2013). A comparative evaluation of E-learning and traditional pedagogical process elements. Technology and Society, 16(3), 76-87 https://www.jstor. org/stable/jeductechsoci.16.3.76. Accessed 12 November 2018.

Veletsianos, G., and Moe, R. (2017). The rise of educational technology as a sociocultural and ideological phenomenon. https://er.educause.edu/articles/2017/4/the-rise-of-educational-technology-as-asociocultural-and-ideological-phenomenon. Accessed 12 November 2018.

Viberg, O., Hatakka, M., Bälter, O., \& Mavroudi, A. (2018). The current landscape of learning analytics in higher education. Computers in Human Behavior, 89, 98-110. https://doi.org/10.1016/j.chb.2018.07.027.

Ward, D. (2018). What's lacking in online learning? Dreyfus , Merleau-Ponty and bodily affective understanding. Journal of Philosophy of Education, Online First Edition. doi:https://doi.org/10.1111/14679752.12305 . 